Altam, S. (2020). Influence of social media on EFL Yemeni learners in Indian Universities during Covid-19 Pandemic. Linguistics and Culture Review, 4(1), 35-47.

https: / / doi.org/ 10.37028/lingcure.v4n1.19

\title{
Influence of social media on EFL Yemeni learners in Indian Universities during Covid-19 Pandemic
}

\section{Saleh Altam}

Dr. Babasaheb Ambedkar Marathwada University, Aurangabad, India

\begin{abstract}
The present study aims to scrutinize the efficiency of using social media on EFL Yemeni learners in Indian universities during the COVID-19 pandemic. This research covers four social media Facebook, Twitter, YouTube, and WhatsApp. The research methodology that is used in this research is quantitative design using an online questionnaire. The questionnaire was distributed online using a closed-ended questionnaire. Google forms were exploited in this study. The findings indicated that learners spend more time using social media for learning the English language, and listening is the most improved skill when using social media for learning the English language. Results also indicated that using social media makes learners acquire and practice new vocabularies and decrease their spelling errors. Finally, YouTube is the most used social media platform for learning the English language. More research is needed to clarify the impact of other social media such as Snapchat, Instagram, Wechat, etc. on EFL learners. Further research is also recommended for investigating the impact of social media on each skill separately.
\end{abstract}

Keywords---Covid-19, EFL Yemeni learners, Indian universities, social media, spelling errors.

\section{Introduction}

The novel coronavirus disease 2019 (COVID-19) developed at the end of December 2019 in Wuhan city of China and has since spread in the world widely. As of 7 May 2020, more than 3.755,379 cases have been testified in 187 countries and regions, resulting in more than 263,831 losses. More than 932000 people have recovered (COVID-19 Dashboard).

The first case of coronavirus pandemic in India was testified on 30 January 2020. As of 7 May 2020, the Indian Ministry of Health and Family Welfare has confirmed a total of 35902 cases. "Experts suggest the number of Infections could

Linguistics and Culture Review (C) 2020.

Corresponding author: Altam, S. Email: altamsaleh@gmail.com

Manuscript submitted: 14 Feb 2020, Manuscript revised: 18 April 2020, Accepted for publication: 09 May 2020 
be much higher as India's testing rates are among the lowest in the world"( BBC. 28 March 2020) India's population is of 1.3 billion. The whole country is locked down. Everything is closed including the institutional establishments like schools and universities. People especially students started to use social media more than any time before because they are confined at their hostels and have more free time. Yemeni students studying in India are no exception, but they also use social media for learning the English language. A language is a tool that we use to communicate with each other; it may be our mother tongue, a second, or a foreign language that we learn. "For many years Language has been regarded as a means of communication among people regardless of their different races and colors. Humans need language as much as they need air, water, and food. There would be no life without that channel which connects people, as it is the basic means of oral communication among individuals, groups and people" (Namaziandost, and Nasri, 2019)

"Language is the divine gift of God. It is the language that distinguishes man from animals. Language is man's finest asset. To the philosophe, the language may be an instrument of thought, for we think through language. When we think we talk to ourselves. Thought involves sub-vocal speech. To the sociologist, a language is a form of behavior_ a behavior of mind in a social context. To the psychologist, a language is a form of activity of mind of basically four types-listening, speaking, reading, and writing." (Dash \& Dash, 2007)

Learning the English language as a foreign language has always been the main concern for Arab students in general and Yemeni EFL learners in particular. Those Yemeni EFL learners who study different academic disciplines in different Indian universities are very keen to improve their efficiency in the English language. The medium of instruction in Indian universities is English so all the foreign students, in general, are obliged to learn English. English occupies a very important place in the world especially in a country like India. It verified to be a great integrating might for bonding the Indians with their varied cultures, religions, and languages. It is said that one person out of every ten in the world is a native speaker of English and one out of every four in the world can be reached with it. Familiarity with English will make a person an inhabitant of the world. It is important for every walk of life today. (Dash \& Dash, 2007)

This is from one hand. On the other hand, all universities and educational institutes are closed now due to lockdown and curfew in the whole world. In an attempt to keep in touch with learning, Yemeni EFL learners in India opt to use online learning using different ICT's like Zoom, YouTube, Facebook, Twitter, WhatsApp, Blogs, etc. Social media takes most of the students' time, so learning via social media seems interesting and new for those learners. However, the extent to which students use social networks for educational purposes is somewhat unidentified.

The importance of this study lies in the fact that it is the first study conducted on Yemeni students studying in Indian universities during the COVID-19 pandemic. 
It contains a real investigation about to what extent social media improves students' efficiency in the English language. The study also presents some advice and ideas for the proper use of social media for educational purposes.

Regarding the main problem of the study, it is crucially important for EFL Yemeni learners studying in India to develop their skills in the English language. When the English language four skills are mastered and acquired, we can say that the EFL learners have captivated the language. Incredibly, the four English language skills can be developed by using social media providing that they are used properly.

Yemeni EFL learners in India are very eager to improve their English language skills, but they are currently locked down at their hostels. The lockdown has been extended for the second time. Lectures and educational programs are no longer conducted till indefinite time due to the COVID-19 pandemic. So there is a desperate need for those EFL learners to continue their education especially English language education. Furthermore, most of the Indian universities did not launch online classes. So more than any time learners need to use social media for educational purposes.

Thus, this study is planned to find answers to the main four research questions

1) Do learners spend too much time using social media?

2) What is the learners' attitude towards social media as a pedagogical and educational tool?

3) Which social media is used the most for learning the English language?

4) Which skill is developed the most when using social media for learning the English language?

\section{Literature review}

It is known that the English language is the language of technology including the Internet. The Web has given rise to what is essentially a modern English variety which is distinct from traditional varieties (Al-Kadi \& Ahmed, 2018). Well-known language researchers, like (Crystal 2001, 2005, 2011) considered Internet English to be a linguistic revolution. According to Crystal, these variations in English form and usage have led to the emergence of a new branch of linguistics. He calls Internet Linguistics. Furthermore, (Presnsky, 2001), mentioned that a digital native designates a person who has grown up in the digital age, rather than having acquired familiarity with digital systems as an adult, as a digital immigrant. So all those who were born from 1980 are considered digital natives and those born before are digital immigrants. So we can say that in the pre-digital age, learning was teacher-centered, but now, in the digital age, it has become selfcentered.

Social media platforms like WhatsApp allows students to practice their English speaking skill without being surrounded by their peers and without being afraid to commit errors and mistakes. In this regard, (Namaziandost \& Nasri, 2019) conducted a study on Iranian EFL learners and teachers to check the impact of 
social media on EFL learners' speaking skill and they found that social media constructs a peaceful context for learners to talk liberally and express their ideas without any fear of awkwardness or lack of self-confidence.

One of the main usages of social media platforms like Facebook is commenting on different posts, texting, and sharing messages. In this regard, (Alotumi, 2015), researched to investigate Yemeni EFL students' perceptions, attitudes, and challenges on integrating Facebook Interaction (FBI) to improve their essay writing and he stated that Facebook interaction helps students to improve their writing and they also acquire new vocabularies and improve spelling.

However, (Ghouali \& Benmoussat, 2019) assumed, on a study conducted on EFL Algerian learners about the effect of social media on EFL students' written production, that " The long exposure to social media leads to the process of fossilization which can be harmful to their acquisition of the structure of the foreign language". They furthermore added that social media affect students damagingly and they use an informal lexicon and make grammar and spelling mistakes. They found that students are addicted to use social media for a long time especially Facebook. This habit led to a deficiency in their writing abilities. They also stated that students encountered an incapability to differentiate between social media context and formal context while writing.

(Al Mubarak, 2016), also conducted a study to inspect the role of social media in learning English as a second language among Saudi Arabian students and he found that majority of the participants utilize social media to develop their communication skills. Furthermore, (White, 2009) stated that social media assisted to increase students' motivation and academic writing in Japan.

There is also a negative influence of social media on students in general in this regard, (Devi et al, 2019) clarified the negative side of social media "Students have become prone to frequent fluctuations in mood and self-control. A recent study has stated that whenever someone uploads a profile picture, it immediately affects the mood of students. It produces stress, anxiety, or fear for them. Students neglect the studies by spending time on the social networking website rather than studying or interacting with the people in person. Students prefer to chat with friends for the hours and this leads to the waste of time that could have been used for study or learning new skills. Students' use of social media regularly may lose their ability to engage in face to face communication. Even though students spend lots of time socializing effectively, it should not hamper their study and academic credential. It should be kept in mind that social networking creates the virtual world, that drastically differs from the reality."

Furthermore, (Crystal, 2001), stated that there is a variability of new nonstandard English spellings that are watched in chat groups or cybernetic world games. They are mainly inclined by speech and symbolize the youth's language in computer-generated worlds. 
Several studies have been conducted to investigate the influence of e-learning on EFL learners in general, but there seems to be few or no research at all investigating impacts of social media on EFL Yemeni learners in India especially during COVID-19 pandemic.

Studies also have not filled the gap of the influence of social media on EFL Yemeni learners in Indian universities. Therefore, this study investigates the influence of social media on EFL Yemeni learners in Indian universities during the COVID-19 pandemic. All Yemeni learners in India are confined at homes and most of their time is spent using social media, so this problem prompted the researcher to investigate the influence of this e-learning.

\section{Method}

To examine and measure the influence of social media on EFL Yemeni learners studying in Indian universities during COVID-19, an online questionnaire was designed to grab the situation of learners' use of social media for learning English as a foreign language. The research methodology that was used in this research was quantitative design using an online questionnaire. The questionnaire included ten items. Out of ten, seven items included with a five-point Likert Scale of 'Strongly agree', Agree', 'Disagree', 'Strongly disagree' Neutral. Three items measure learners' attitudes towards social media. Participants were 120 Yemeni learners studying in India in different Indian universities. Those participants were cooperative to large extents and they interacted fully with the questionnaire's different items.

Google Forms were used in this study. A link was sent to different WhatsApp groups. Those groups belong to Yemeni students studying in India. The link was sent to those groups accompanied by a message requesting students to fill up the questionnaire. The link was seen by hundreds of students and only those who were interested in the research topic interacted. The study used the software (SPSS) to analyze the gathered data.

\section{Discussion}

The demographic information was not included in the study because all the participants were males and the age of the participants makes no difference in the results obtained from the questionnaire. Participants were not also asked to state their identities. The results portrayed below are the students' responses to the questionnaire designed to answer the study's questions.

\section{Time spent using social media}

The first item of the questionnaire was a question asking the participants how much time do they spend using social media during the COVID-19 pandemic. (107) out of (120) participants stated that they use social media for more than 4 hours daily. (13) Participants stated that they use social media for 1 to 2 hours daily which constitutes only $(10.8 \%)$ of the participants. From the answers 
obtained from the participants for the first item of the questionnaire, it is clear that the majority of the learners $(89.1 \%)$ use social media excessively. This indicates that learners use social media too much especially during the COVID-19 pandemic. This long time spent daily with social media is because of the free and unlimited time learners have during the pandemic.

\section{Learners' attitudes toward social media as an educational and pedagogical tool}

Seven items of the questionnaire were designed according to the Likert Scale. Seven items included with a five-point Likert Scale of 'Strongly agree', Agree', 'Disagree', 'Strongly disagree' Neutral. Measurement Proposed by Hanson et al was implemented (Hanson et al., 2005). According, to these studies, the mean scores of agreements range from 1.00 to 2.33 are interpreted as low motivation, mean scores of agreements range from 2.34 to 3.67 are interpreted as a moderate level of motivation, and mean scores of agreements range from 3.68 to 5.00 are interpreted as a high level of motivation. The study used the software (SPSS) to investigate the gathered data.

Table 1, shows repetitions and percentages of the responses of the participants

\begin{tabular}{|c|c|c|c|c|c|c|c|c|c|c|}
\hline \multirow{2}{*}{\multicolumn{2}{|c|}{ Questionnaire items }} & \multicolumn{5}{|c|}{ Participants' responses } & \multirow[b]{2}{*}{ Mean } & \multirow{2}{*}{$\begin{array}{l}\text { Std. } \\
\text { Deviation }\end{array}$} & \multirow[b]{2}{*}{ RANK } & \multirow{2}{*}{$\begin{array}{l}\text { General } \\
\text { trend }\end{array}$} \\
\hline & & $\begin{array}{c}\begin{array}{c}\text { Strongly } \\
\text { disagree }\end{array} \\
2 \\
\end{array}$ & $\begin{array}{c}\text { Disagree } \\
6\end{array}$ & $\begin{array}{c}\text { Neutral } \\
6\end{array}$ & $\begin{array}{c}\text { Agree } \\
79\end{array}$ & $\begin{array}{c}\begin{array}{l}\text { Strongly } \\
\text { agree }\end{array} \\
27\end{array}$ & & & & \\
\hline $\begin{array}{l}\text { media makes me } \\
\text { acquire and } \\
\text { practice new } \\
\text { vocabularies in } \\
\text { the English } \\
\text { language. }\end{array}$ & $\%$ & 1.7 & 5.0 & 5.0 & 65.8 & 22.5 & 4.03 & .793 & 2 & Agree \\
\hline \multirow{2}{*}{$\begin{array}{l}\text { 2. Using social } \\
\text { media makes me } \\
\text { develop and } \\
\text { decrease my } \\
\text { spelling errors. }\end{array}$} & $\mathrm{N}$ & 5 & 12 & 15 & 71 & 17 & \multirow[b]{2}{*}{3.69} & \multirow[b]{2}{*}{.977} & \multirow[b]{2}{*}{6} & \multirow[b]{2}{*}{ Agree } \\
\hline & $\%$ & 4.2 & 10.0 & 12.5 & 59.2 & 14.2 & & & & \\
\hline \multirow{2}{*}{$\begin{array}{l}\text { 4. Social media } \\
\text { helps me improve } \\
\text { my English } \\
\text { fluency. }\end{array}$} & $\mathrm{N}$ & 1 & 10 & 7 & 83 & 19 & \multirow[b]{2}{*}{3.91} & \multirow[b]{2}{*}{.789} & \multirow[b]{2}{*}{4} & \multirow[b]{2}{*}{ Agree } \\
\hline & $\%$ & 0.8 & 8.3 & 5.8 & 69.2 & 15.8 & & & & \\
\hline \multirow{2}{*}{$\begin{array}{l}\text { 5. Using social } \\
\text { media helps me } \\
\text { improve my skills } \\
\text { in the English } \\
\text { language. }\end{array}$} & $\mathrm{N}$ & 1 & 7 & 4 & 77 & 31 & \multirow[b]{2}{*}{4.08} & \multirow[b]{2}{*}{.773} & \multirow[b]{2}{*}{1} & \multirow[b]{2}{*}{ Agree } \\
\hline & $\%$ & 0.8 & 5.8 & 3.3 & 64.2 & 25.8 & & & & \\
\hline
\end{tabular}




\begin{tabular}{|c|c|c|c|c|c|c|c|c|c|c|}
\hline \multirow{2}{*}{$\begin{array}{l}\text { 6. I waste my time } \\
\text { when I use social } \\
\text { media. }\end{array}$} & $\mathrm{N}$ & 5 & 27 & 7 & 62 & 19 & \multirow[b]{2}{*}{3.53} & \multirow[b]{2}{*}{1.130} & \multirow[b]{2}{*}{7} & \multirow[b]{2}{*}{ Agree } \\
\hline & $\%$ & 4.2 & 22.5 & 5.8 & 51.7 & 15.8 & & & & \\
\hline \multirow[b]{2}{*}{$\begin{array}{l}\text { 7. Using social } \\
\text { media develops } \\
\text { my interaction } \\
\text { with } \\
\text { classmates and } \\
\text { lecturers, } \\
\text { accordingly, it } \\
\text { helps me to } \\
\text { improve my } \\
\text { academic } \\
\text { performance. }\end{array}$} & $\mathrm{N}$ & 1 & 10 & 12 & 78 & 19 & & & & \\
\hline & $\%$ & 0.8 & 8.3 & 10.0 & 65.0 & 15.8 & 3.87 & .809 & 5 & Agree \\
\hline \multicolumn{7}{|l|}{ Overall } & 3.86 & .496 & \multicolumn{2}{|c|}{ Agree } \\
\hline
\end{tabular}

Table 1 shows the repetitions and percentages of the responses of the participants to the questionnaire items. Here, the researcher discusses only 4 items the highest and the lowest. The rest of the items are understood from table number 1 .

Item No. 5 got the first rank with a mean (4.08) which indicates that learners hold a high attitude and motivation for the use of social media as an educational tool for learning the English language. The total consent replies for this item are (108) out of (120) which constitutes (90\%) of the participants.

Item No. 1 got the second rank with a mean (4.03) which indicates also a high and a positive attitude and motivation towards social media as an educational tool for learning English. The total consent replies for this item are (106) out of (120) which constitutes (88\%) of the participants. The item which got the lowest rank is item No. 6. The mean for this item is (3.53) and total consent replies are (81) out of (120) which constitutes (\%67.5) of the participants. The second-lowest rank is item No. 2. The mean for this item is (3.69) and total consent replies are (88) out of (120) which constitutes (\% 73.4) of the participants.

From table number 1 , it is clear that the mean of the total items is (3.86) and it indicates that learners hold a high level of agreement and motivation for the use of social media for learning English. Participants showed a high agreement on the questionnaire items. This finding answers the study's question number two (What is learners' attitude towards social media as a pedagogical and educational tool?) Learners' attitude is that majority of them hold a high level of motivation to use social media as an educational tool to learn the English language.

Based on the finding, Yemeni EFL learners studying in India are enthusiastic to use social media to learn the English language. They feel that they improve their English when using social media. They feel that they acquire and practice new vocabularies in the English language. They also feel that they develop and decrease their spelling errors. This agrees with the findings reached by (Alotumi, 2015), who found that Facebook interaction helps students to improve their writing, acquire new vocabularies, and improve spelling. 
The findings indicate also that learners feel that using social media for learning the English language is entertaining and exciting. This because of the fashionable and attractive design of social media. Another important indication of the finding is that learners feel that using social media improves their fluency and interaction with their peers. Learners can speak freely and without barriers when using social media platforms like WhatsApp, and Messenger. So social media makes them socialize and practice speaking in the English language especially when making friends with English native speakers on Facebook or WhatsApp.

Finally, the findings indicate that nearly half of the learners feel that their time is wasted when using social media. This is the challenge faced by learners. They should know how to use social media wisely and properly. It should be noted that social media websites can be accessed effortlessly; they are free and eye-catching to users. Social media is not only used for learning, but it is also used for so many purposes such as entertaining, paid advertising, gaming, checking on friends, watching friends' status, etc. So these multi uses of social media may make a learner stop using social media for learning and use it for entertaining. When studying, learners always give themselves a break and this break is using social media for checking news and friends. This is normal; however, learners sometimes forget the time and use social media excessively for entertainment especially during the COVID-19 pandemic.

\section{The statistical analysis for the most used social media for learning the English language}

To find an answer for the study question about which social media is used the most for learning the English language, the researcher analyzed the participants' responses through the Statistical Analysis Program (SPSS) and obtained the results shown in Table No. (2).

Table No. 2, shows the most used social media for learning the English language

\begin{tabular}{llll}
\hline & Frequency & Percent \\
\hline Valid & YouTube & 98 & 81.7 \\
& Facebook & 15 & 12.5 \\
& WhatsApp & 5 & 4.2 \\
& Twitter & 2 & 1.7 \\
& Total & 120 & 100.0 \\
\hline
\end{tabular}

Table No. 2 shows the results of descriptive statistics on the frequency and percentages of the participants' replies. From table number (2) it is clear that the most social media platform used for learning the English language is YouTube. 
The users of this social media are (98) out of (120) which constitutes $(81.7 \%)$ of the participants. The next most used social media for learning the English language is Facebook. The users of Facebook are (15) out of (120) participants, and that constitutes $(12.5 \%)$ of participants. The least used social media for learning the English language is Twitter. The users of Twitter are only (2) participants out of (120) participants and that constitutes only $(1.7 \%)$ of participants. Figure No. (1) illustrates this.

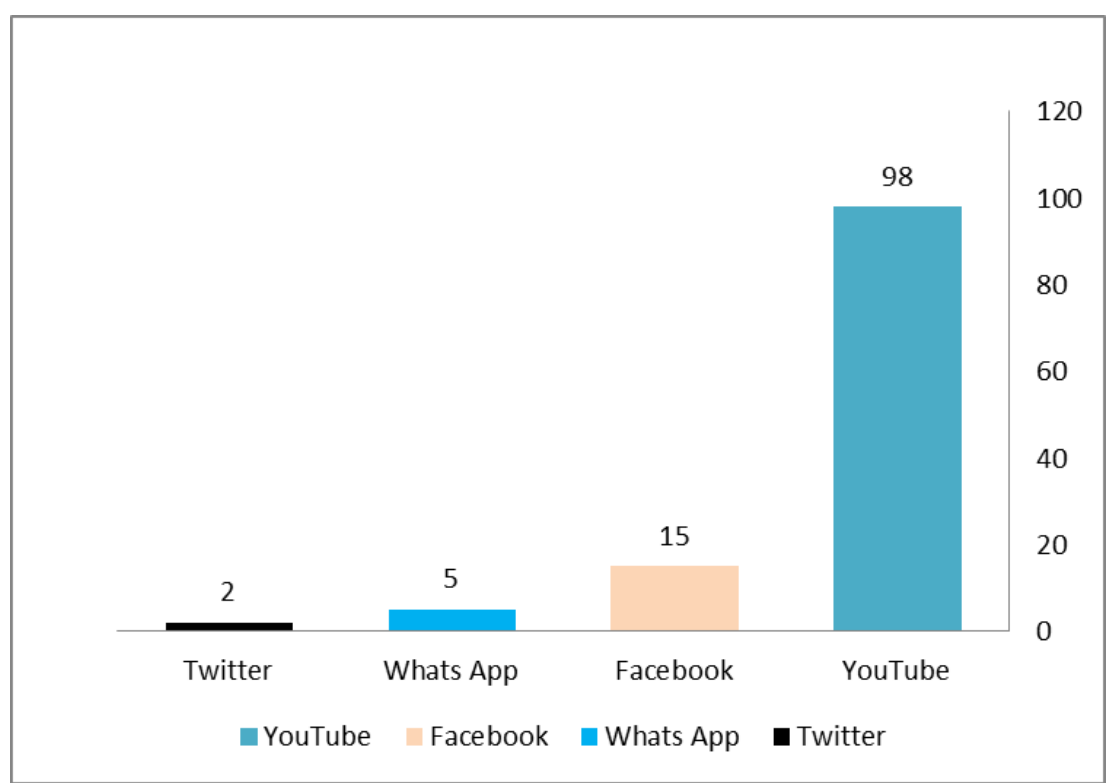

Figure 1. Illustrates the most used social media for learning the English language

From figure number (1), it is clear that YouTube is the most used social media platform for learning the English language. The use of YouTube can play an essential part in helping learners understand English.

YouTube is an instrument that simplifies language learning and teaching and confidence building, as well as gives reliable student-centered activities (Brook, 2011; Wrigglesworth, 2012; Golonka, 2014). YouTube had 2 billion users worldwide, over 2 Billion logged-in users visit YouTube each month, and every day people watch over a billion hours of video and generate billions of views. (YouTube About). YouTube can play an essential part in helping learners comprehend English lessons, increase their performance, and progress their comprehending of English. YouTube website can be an effective method in dealing with students' complications and obstacles in understanding English. It is regarded to be more effective and successful than textbook-based English courses in promoting better learning of English (Almurashi, 2016; Al-Jaro et al, 2017 ).

There are many English videos available on YouTube that can be used for learning the English language. It can be used in numerous ways for effective learning. It is not only useful to enhance speaking and listening skills but also to teach reading and writing skills. YouTube can be a treasured tool through which various 
language skills can be taught. YouTube videos can be used to make the learners focused on the varieties of English spoken around the globe and to afford them with reliable resources for speaking skills. (Jalaluddin, 2016).

\section{The most developed skill when using social media for English language learning}

To discover which skill is developed the most when using social media for English language learning, the researcher analyzed the participants' replies statically using (SPSS) and obtained the result shown in table number (3).

Table 3, shows the most developed skill when using social media for learning English.

\begin{tabular}{llll}
\hline & & Frequency & Percent \\
\hline Valid & Reading & 22 & 18.3 \\
& Listening & 69 & 57.5 \\
Writing & 4 & 3.3 \\
& Speaking & 25 & 20.8 \\
& Total & 120 & 100.0 \\
\hline
\end{tabular}

Table No. (3) shows the results of descriptive statistics on the frequency and percentages of the participants' replies. From table number (3), it is clear that the most developed skill when using social media for English language learning is listening. The participants who selected listening as the most developed skill is (69) out of (120) which constitutes (57.5\%) of the participants of the questionnaire. The next skill is speaking. The number of participants who chose this skill is (25) out of (120) which constitutes $(20.8 \%)$ of the participants of the questionnaire.

The least developed skill when using social media for English language learning is writing. The number of participants who selected this skill is only (4) out of (120) participants which constitute $(3.3 \%)$ of the participants of the questionnaire. Figure number (2) illustrates this. 
Figure 2. Illustrates the most developed skill when using social media for E. learning.

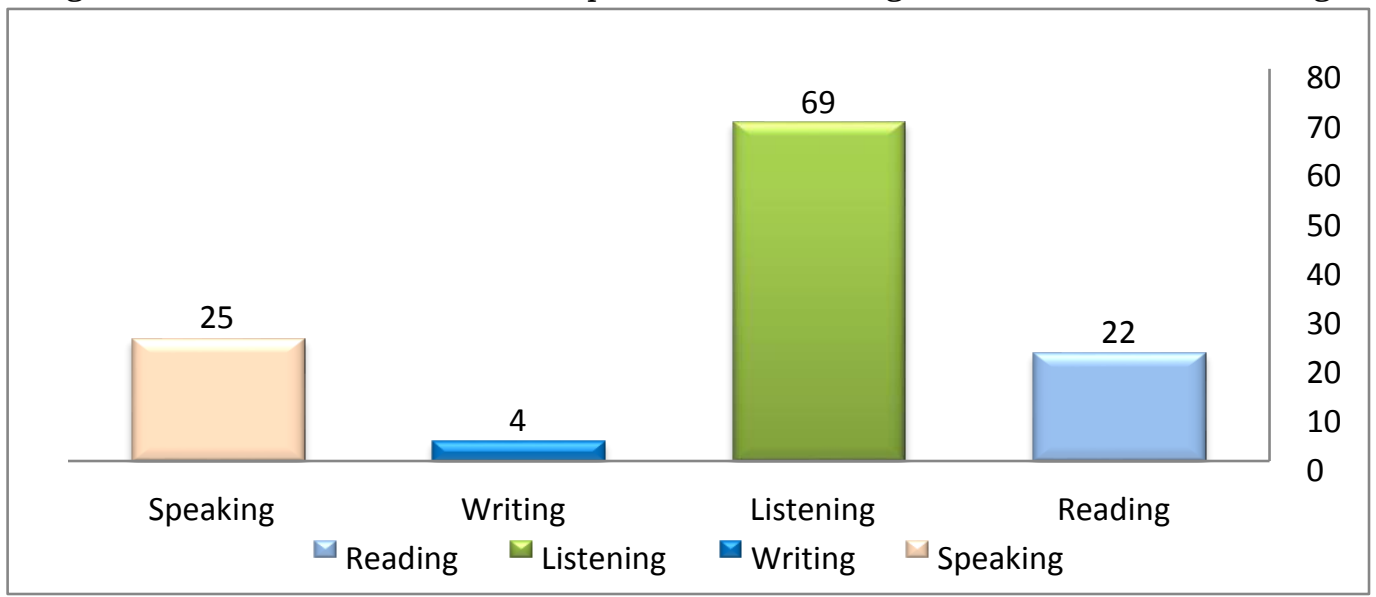

From figure No. 2, it is clear that the most developed skill when using social media for English language learning is listening. Listening is a skill, thus it can be developed through using social media. Listening competence is a skill and it is developed simultaneously with frequent use of social media especially when listening to native speakers on YouTube. Listening is the essential skill providing the basis for effective communication and a successful professional job. Effective listening skills improve the capability to learn and adapt new information, knowledge, and skills (Liubinienè, 2009; Qi et al, 2015).

Speaking can also be developed when using social media for English language learning. Learners can practice speaking in English with their peers and friends and that may develop their pronunciations competence. Participants selected writing as the least developed skill in the sense that they do not practice writing paragraphs or essays on social media. They do decrease their spelling errors and acquire vocabularies, but they do not practice writing paragraphs or essays as they used to write academically.

\section{Conclusion}

From this study of the influence of social media on (120) Yemeni learners of EFL in Indian universities during COVID-19, it looks obvious that those learners spend more time using social media than before. Social media has become a crucial part of their everyday life and it has become also a daily habit among them especially during the pandemic. Learners' replies indicate that they use social media for learning English frequently and they feel that they improve their listening skills when using social media more than the other skills like reading, writing, and speaking. Social media, in particular, can be used to develop learners' speaking capabilities. The responses of the participants of the study also 
reflected that using social media benefits them to acquire and practice new vocabularies and it also helps them to decrease their spelling errors. Learners also perceive YouTube as the most social media used for learning the English language especially for improving their fluency and their listening skills. Furthermore, learners' attitude towards social media platforms as a pedagogical tool is positive; they feel that their interaction with lecturers and classmates is improved and this improvement leads to overall improvements in their academic performance. The findings also revealed that learners feel that using social media for learning English is entertaining and exciting, but some learners confessed that they waste their time when using social media in general and this may be the disadvantage and main challenge of social media because learners do not feel the passage of time when using social media especially when chatting with friends. So we may welcome this use of social media for learning English, but we have to be careful of the disadvantages. To sum up, the study addressed the influence of social media on learners in general and during the COVID-19 pandemic. Further investigations on the topic should be addressed and be held by future researchers who may investigate the influence of social media on each skill separately so that a wider perspective can be revealed. So this study opens a door for furthers research on the same topic and future studies similar to this study may overcome limitations of this study.

\section{References}

Al Mubarak, A. A. (2016). Learning English as a second language through social media: Saudi Arabian tertiary context. International Journal of Linguistics, 8(6), 112-127.

Al-Jaro, M., Asmawi, A., \& Hasim, Z. (2017). Content analysis of the pedagogical content knowledge in the curriculum of Yemeni EFL teacher education programme. Arab World English Journal (AWEJ) Volume, 8.

Al-Kadi, A. M. T., \& Ahmed, R. A. (2018). Evolution of English in the internet age. Indonesian Journal of Applied Linguistics, 7(3), 727-736. https://doi.org/10.17509/ijal.v7i3.9823

Almurashi, W. A. (2016). The effective use of YouTube videos for teaching English language in classrooms as supplementary material at Taibah University in Alula. International Journal of English Language and Linguistics Research, 4(3), 32-47.

Alotumi, M. (2015). Facebook Interaction (FBI) and essay writing pre-task: Yemeni

EFL students' perceptions, attitudes and challenges. SSRN Electronic Journal January 2015 (February 27, 2015). https://dx.doi.org/10.2139/ssrn.3185696

Brook, J. (2011). The affordances of YouTube for language learning and teaching. Hawaii Pacific University TESOL Working Paper Series, 9(1), 2.

COVID-19 Dashboard By The Center for Systems Science and Engineering (CSSE) at Johns Hokins University (JHU)

Crystal, D. (2001). Language and the Internet. Cambridge: Cambridge University Press.

Crystal, D. (2005). The scope of Internet linguistics. In Proceedings of American Association for the Advancement of Science Conference; American Association for the Advancement of Science Conference, Washington, DC, USA (pp. 17-21). 
Crystal, D. (2011). Internet linguistics: A student guide. Routledge.

Dash, N., \& Dash, M. (2007). Teaching English as an additional language. Atlantic Publishers \& Dist.

Devi, K., Gouthami, E., \& Lakshmi, V. (2019). Role of Social Media in TeachingLearning Process. Retrieved from Journal of Emerging Technologies and Innovative Research (JETIR), 6(2), 96-103.

Ewa M. Golonka, Anita R. Bowles, Victor M. Frank, Dorna L. Richardson \& Suzanne Freynik (2014) Technologies for foreign language learning: a review of technology types and their effectiveness, Computer Assisted Language Learning, 27:1, 70-105, DOI: 10.1080/09588221.2012.700315

Ghouali, K., \& Benmoussat, S. (2019). Investigating the Effect of Social Media on EFL Students' Written Production: Case of Third-Year EFL Students at

Tlemcen University, Algeria. In Arab World English Journal (AWEJ) May 2019 Chlef University International Conference Proceedings.

https: / /dx.doi.org/10.2139/ssrn.3400418

Hanson, W. E., Creswell, J. W., Clark, V. L. P., Petska, K. S., \& Creswell, J. D. (2005). Mixed methods research designs in counseling psychology. Journal of counseling psychology, 52(2), 224.

https:/ / psycnet.apa.org/doi/10.1037/0022-0167.52.2.224

Jalaluddin, M. (2016). Using YouTube to enhance speaking skills in ESL classroom. English for Specific Purposes World, 17, 50.

Jonathan Wrigglesworth (2020) Using smartphones to extend interaction beyond the EFL classroom, Computer Assisted Language Learning, 33:4, 413-434, DOI: 10.1080/09588221.2019.1569067

Liubinienè, V. (2009). Developing listening skills in CLI. Kalbu studijos, (15), 8993.

Namaziandost, E., \& Nasri, M. (2019). The impact of social media on EFL learners' speaking skill: a survey study involving EFL teachers and students. Journal of Applied Linguistics and Language Research, 6(3), 199-215.

Prensky, M. (2001). Fun, play and games: What makes games engaging. Digital game-based learning, 5(1), 5-31.

White, J. (2009). The use of Facebook to improve motivation and academic writing. In Proceedings of the Third International Wireless Ready Symposium (pp. 28-32).

"Coronavirus: India defiant as millions struggle under lockdown" BBC. 28 March 2020.

Yu-Jie Qi, Yan Sun, De-Zheng Feng (2015) New Media and English Language Teaching in China: A Case Study based on Multiliteracies Pedagogy TESOL International Journal Vol. 10 Issue 1 ISSN 2094-3938! 